\title{
EFFECTS OF EXPOSURE TIME AND EXPOSURE DISTANCE ON THE MICRO-MECHANICAL PROPERTIES OF LIGHT CURED PIT AND FISSURE SEALANTS
}

\author{
Maria Holroyd ${ }^{1 a}$, Nicoleta llie $^{16 *(10)}$ \\ 'Department of Operative Dentistry and Periodontology, University Hospital, Ludwig-Maximilians University Munich, Goethestr. 70, D-80336 Munich, \\ Germany \\ ${ }^{a} D D S$, PhD Student \\ bDipl Eng, PhD, Professor
}

DOI: https://doi.org/10.25241/stomaeduj.2019.6(1).art.1

Introduction: The study aimed to perform comparative measurements on the effect of exposure time and exposure distance on the micro-mechanical properties Vickers hardness (HV) and indentation modulus (E) of light cured, resin-based pit and fissure sealants.

Material and Methods: Thirteen pit and fissure sealants were selected. Combinations of three clinically relevant exposure times $(10,20,40 \mathrm{~s})$ and two, fixed sample - light source exposure distances ( 4 and $7 \mathrm{~mm}$ ) were tested. The HV and E of each group $(n=6)$ were measured with an automatic hardness indenter. Data were analyzed by a multi-variant analysis and partial eta-squared $\left(\eta_{\mathrm{p}}{ }^{2}\right)$ statistic.

Results: The factor "material" had the most significant influence (significance level $a \leq$ 0.05 ) on the measured micro-mechanical properties $E$ and HV as shown by a $\eta^{2}$ statistic $\left(\eta_{p}^{2}=0.939\right.$ and 0.927 respectively). The factor "exposure time" had a significant but moderate influence on both material properties $E$ and $\mathrm{HV}\left(\mathrm{n}_{\mathrm{p}}{ }^{2}=0.297\right.$ and 0.084$)$ whereas a smaller but significant effect of the factor "exposure distance" was only observed for $E$ $\left(n_{p}^{2}=0.049\right)$.

Conclusions: Properties E and HV are strongly influenced by the type of sealant. On the other hand, the exposure distance had a low influence on these, whilst the exposure time had a greater influence. Exposure time and to a lesser extent exposure distance have a significant effect on the micro-mechanical properties of pit and fissure sealants.

Practical Implications: We conclude these findings indicate exposure time to be more significant when considering clinical application of these materials.

Keywords: Pit and fissure sealants; micro-mechanical properties; pediatric dentistry; dental materials; curing.

OPEN ACCESS This is
Oan Open Access article under
the CC BY-NC 4.0 license.
Peer-Reviewed
Article
Citation: Holroyd M, llie N. Effects
of exposure time and exposure
distance on the micro-mechanical
properties of light cured pit and
fissure sealants. Stoma Edu J.
2019;6(1):9-17
Received: January 21, 2019
Revised: February 12, 2019
Accepted: February 19, 2019
Published: February 21, 2019
Corresponding author:
Nicoleta llie, Dipl Eng, PhD,
Professor at the Department
of Operative Dentistry and
Periodontology, University Hospital,
Ludwig-Maximilians University
Munich Goethestr.70
D-80336 Munich, Germany
Phone: + +49-89-44005-9412
Fax: + +49-89--44005-9302
e-mail: nilie@dent.med.uni-
muenchen.de
Copyright: @ 2019 the Editorial
Council for the Stomatology Edu
Journal.

\section{Introduction}

Initial descriptions in the applicative use of pit and fissure sealants were published in the late 1960's [1] whilst retention rates of such sealants were evaluated in the 1980's, clearly demonstrating the benefits and effectiveness of the treatment [2-5]. In many cases the placement of pit and fissure sealant in a clinical setting is not clearly indicated. An America Dental Association (ADA) report published in 2008 [6] gave a number of recommendations to help dental practitioners with their decision making. This took into account not only the type of material, but also focused on placement techniques and emphasized the importance of periodical caries risk re-evaluation. How different pit and fissure sealant formulations performed in clinical retention studies has been analyzed by conducting a broad metaanalysis of published works [7]. This allowed two central statements to be drawn that conclude light polymerizing materials offer the better combination of performance in measures of five-year retention and practical ease of use in the clinical setting.

Modern, commercially available pit and fissure sealants come in a wide range of formulations which bear direct relevance in their application in the clinical setting [8]. For example, some sealants are transparent whilst others are opaque and have a distinctly different coloration to the tooth e.g. white. Indeed, it has been demonstrated in clinical studies that opaque sealants allow a more reliable clinical assessment of retention [9] whilst facilitating a significantly more accurate identification of sealant treated teeth [10]. Sealants also have a wide spread variability in the degree of filler content.

Sealant failure can typically be attributed to a number of factors that include multiple aspects of their clinical application to the tooth surface. For example, adequate preparations to ensure the exclusion of moisture (saliva) [11] or appropriate acid etching times that create favorable, sponge-like structures with greatly increased surface area [12] full stop. Such precautions and clinical diligence lead to increased micro-mechanical adhesion of the sealant, and reduced marginal fissures. Inappropriate control of occlusion to antagonists are also a source of sealant failure especially for materials that do not contain 

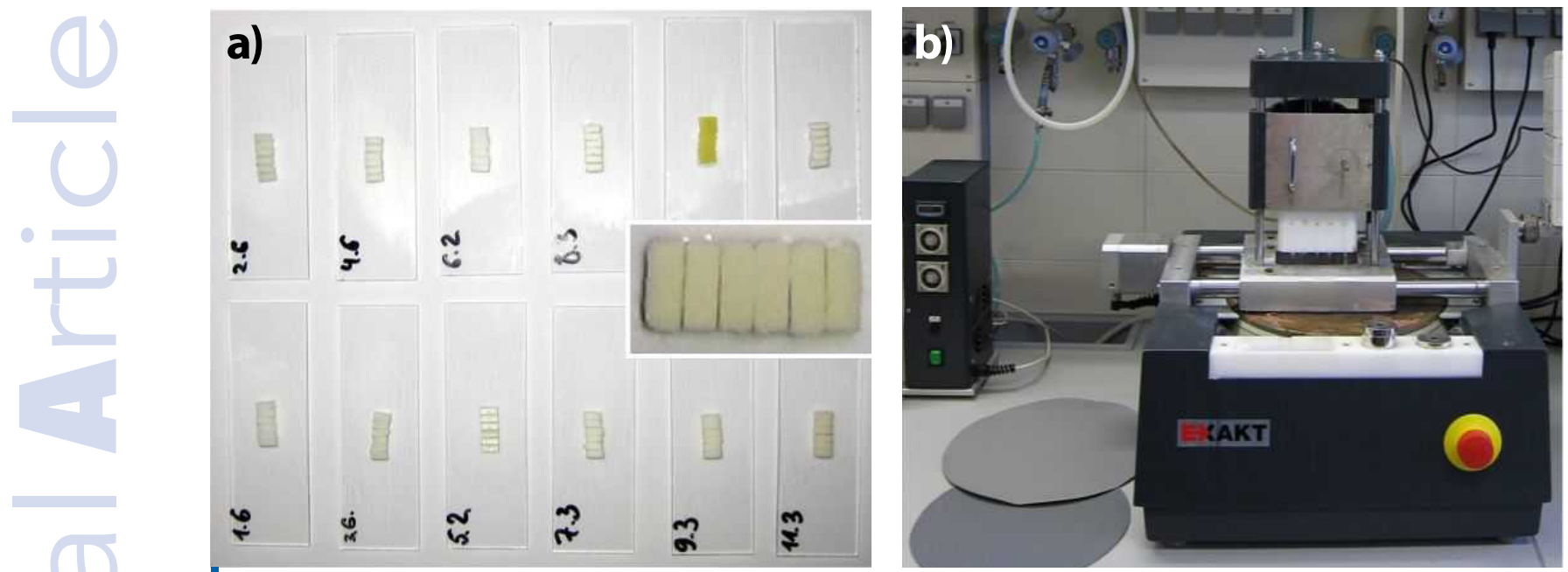

Figure 1. Preparation of fissure sealant samples for micro-mechanical measurements: a) specimen preparation for grinding; b) grinding procedure and device.

filler as these readily fail due to mechanical stress and abrasional forces $[13,14]$. Polymerization in resin based, light cured dental materials is an important factor that determines the quality, effectiveness and longevity of the clinical restorations [15] - indeed in this respect pit and fissure sealants are no different from their other material counterparts. Typically, polymerization will be affected by a number of aspects that are influenced by a range of interacting factors. These include, for example, the irradiance and spectral character of the light curing unit, material specific traits and formulation such as color, opacity, filler properties and monomer composition, the irradiation time and method such as a soft start polymerization program, absolute intensity level at the material surface, or pulsed light mode.

LED technology has established itself as the medium of choice in dental curing units and most contemporary devices use this type of light source. Typically, the peak emission is centered at a wavelength $(470 \mathrm{~nm})$ that has been selected for the optimal activation of camphor quinone [16]. Indeed, this is the most common photo-initiator substance employed in dental sealants. For an extensive review of dental photo-curing please refer to the publication by F. A. Rueggeberg [17]. The characteristics and efficiency of such devices was intensively investigated [18]. Interestingly for the purposes of this current study, based on the results published by Rencz et al. [18], the light curing unit Elipar Freelight 2 (3M ESPE) provided approximately 70 and $40 \%$ of the incident irradiance $(1400 \mathrm{~mW} /$ $\mathrm{cm}^{2}$ ) at an exposure distance of $4 \mathrm{~mm}$ and $7 \mathrm{~mm}$ respectively. These values correspond to ca. 1000 $\mathrm{mW} / \mathrm{cm}^{2}$ at the $4 \mathrm{~mm}$ geometry and $600 \mathrm{~mW} / \mathrm{cm}^{2}$ at the $7 \mathrm{~mm}$ distances employed in the present study. An irradiance of $1000 \mathrm{~mW} / \mathrm{cm}^{2}$ is a value that has been previously identified as a suggested upper limit for the polymerization of resin-based composites (RBCs). This is in part due to the photochemistry of the activator where conversion to the excited state is not the rate limiting process, rather its conversion and reaction (or decay) is kinetically limited. In this case increasing irradiance levels lead to its rapid saturation [19]. Furthermore, high irradiance levels $\left(>1000 \mathrm{~mW} / \mathrm{cm}^{2}\right)$ have been shown to have a detrimental effect on micromechanical properties of light cured materials. Current hypothetical models suggest that if the period between attaining the gelpoint and the initiation of polymerization is too short, internal stress build-up is not allowed to dissipate by a process of material "flow" [20]. Interestingly, earlier research suggested that irradiation time and irradiance level follow a simple reciprocal association $[21,22]$. This lead to the assumption that exposure times of less than $5 \mathrm{~s}$ are adequate to produce a cured material with optimal micro-mechanical properties. However, in the literature it is argued that such a relationship is a too simplified model to describe observed material and chemical behavior under such conditions [19,21]. Given that, for other materials of this class, the degree of cure as a function of the exposure time or exposure distance between the curing unit light guide exit aperture and sample has an influence on their material properties, we chose in the current study to quantify how typical micromechanical properties vary with exposure time and exposure distance. For this purpose, a selection of thirteen commercially available pit and fissure sealants were chosen (refer to Table 1 for details) and investigated. Two exposure distances were selected of $4 \mathrm{~mm}$ and $7 \mathrm{~mm}$ to simulate clinical conditions. 4 $\mathrm{mm}$ was chosen to represent a typical distance that is achieved when the aperture of the curing unit rests upon the cusps of the molar tooth. The $7 \mathrm{~mm}$ position represents a no contact position when the curing unit aperture is held above, but close to the tooth. The following null hypothesis was proposed and tested: Firstly, (a) that increasing the exposure distance between the light guide aperture of the curing unit and the sample surface would not affect the micro-mechanical properties. Secondly, (b) that an increased exposure time would have no influence on the micro-mechanical properties attained and thirdly (c) that the material employed does not influence the micro-mechanical characteristics.

\section{Materials and Methods}

Thirteen resin-based pit and fissure sealants (refer to Table 1 for details) were investigated by assessing the micro-mechanical properties by varying irradiation 
Table 1. Summary of the dental pit and fissure sealants compared in this study (Manufactures specifications).

\begin{tabular}{|c|c|c|c|}
\hline Brand & $\begin{array}{l}\text { Manufacturer } \\
\text { (LOT Nr.) }\end{array}$ & Composition & Curing \\
\hline Clinpro & $\begin{array}{l}\text { 3M ESPE } \\
\text { (N333694) }\end{array}$ & $\begin{array}{l}\text { Matrix: Bis-GMA/TEGDMA } \\
\text { Filler: } \mathrm{n} / \mathrm{a} \\
\text { Fluorid: Yes } \\
\text { Light yellow }\end{array}$ & Light \\
\hline Delton & $\begin{array}{l}\text { Dentsply } \\
(111003)\end{array}$ & $\begin{array}{l}\text { Matrix: } \mathrm{n} / \mathrm{a} \\
\text { Filler: Siliciumdioxide } \\
\text { Fluorid: No } \\
\text { (White) }\end{array}$ & Light \\
\hline Delton FS+ & $\begin{array}{l}\text { Dentsply } \\
(100218)\end{array}$ & $\begin{array}{c}\text { Matrix: Bis-GMA/TEGDMA } \\
\text { Filler: } 53 \% \text { wt. Barium-Aluminium-F-Br-Silica-Glass } \\
\text { Fluorid: No } \\
\text { (White) }\end{array}$ & Light \\
\hline Dyract-seal & $\begin{array}{c}\text { Dentsply } \\
\text { (0908001309) }\end{array}$ & $\begin{array}{c}\text { Matrix: PENTA/ DMAEMA/ DEGDMA } \\
\text { Filler: St-Al-FI-Silica Glas } \\
\text { Fluorid: Yes } \\
\text { (White) }\end{array}$ & $\begin{array}{l}\text { Light/ Chemical } \\
\text { (Compomer) }\end{array}$ \\
\hline $\begin{array}{l}\text { Embrace } \\
\text { Wetbond }\end{array}$ & $\begin{array}{l}\text { Pulpdent } \\
(100218)\end{array}$ & $\begin{array}{c}\text { Matrix: Urethandimethacrylate } \\
\text { Filler: } 43 \% \text { wt. Mixture of hydrophilic and } \\
\text { hydrophobic materials } \\
\text { Fluorid: Yes } \\
\text { (Yellow/white) }\end{array}$ & Light \\
\hline Fissurit-F & $\begin{array}{c}\text { Voco } \\
(1012227)\end{array}$ & $\begin{array}{c}\text { Matrix: Bis-GMA, UDMA } \\
\text { Filler: } 9.5 \% \text { wt. Siliciumdioxide } \\
\text { Fluorid:Yes } \\
\text { (White) }\end{array}$ & Light \\
\hline Grandio Seal & $\begin{array}{c}\text { Voco } \\
(1024382)\end{array}$ & $\begin{array}{l}\text { Matrix: Bis-GMA, TEGDMA } \\
\text { Filler: } 70 \% \text { wt. } \\
\text { Fluorid: Yes } \\
\text { (Yellow/while) }\end{array}$ & Light \\
\hline Helioseal & $\begin{array}{l}\text { Ivoclar Vivadent } \\
\quad \text { (P46901) }\end{array}$ & $\begin{array}{l}\text { Matrix: Bis-GMA, TEGDMA } \\
\text { Filler: } n / a \\
\text { Fluorid: No } \\
\text { (White) }\end{array}$ & Light \\
\hline Helioseal Clear & $\begin{array}{l}\text { Ivoclar Vivadent } \\
\quad \text { (P83091) }\end{array}$ & $\begin{array}{l}\text { Matrix: Bis-GMA, TEGDMA } \\
\text { Filler: } \mathrm{n} / \mathrm{a} \\
\text { Fluorid: No } \\
\text { (Transparent) }\end{array}$ & Light \\
\hline Helioseal F & $\begin{array}{l}\text { Ivoclar Vivadent } \\
\quad(\mathrm{P} 60584)\end{array}$ & $\begin{array}{c}\text { Matrix: Bis-GMA, TEGDMA, UDMA } \\
\text { Filler: } 20 \% \text { wt. F-silica-glass, } \\
21.5 \% \text { wt. Silica } \\
\text { Fluorid: Yes } \\
\text { (White) }\end{array}$ & Light \\
\hline Ionosit Seal & $\begin{array}{c}\text { DMG } \\
(635691)\end{array}$ & $\begin{array}{l}\text { Matrix: } n / a \\
\text { Filler: Ionomerglass } \\
\text { Fluorid: Yes } \\
\text { (White) }\end{array}$ & $\begin{array}{l}\text { Light / Chemical } \\
\text { (Compomer) }\end{array}$ \\
\hline Teethmate F1 & $\begin{array}{l}\text { Kuraray } \\
(00118 C)\end{array}$ & $\begin{array}{c}\text { Matrix: Methacryloyloxydecyldihydrogenphosphate } \\
\text { Filler: }<10 \% \mathrm{wt} \text {. } \\
\text { Fluorid: Yes } \\
\text { (Transparent) }\end{array}$ & Light \\
\hline $\begin{array}{l}\text { Ultraseal XT } \\
\text { plus }\end{array}$ & $\begin{array}{l}\text { Ultradent } \\
\text { (B4S8F) }\end{array}$ & $\begin{array}{l}\text { Matrix: Bis-GMA, Diurethandimethacrylate } \\
\text { Filler: } 58 \% \text { wt. } \\
\text { Fluorid: Yes } \\
\text { (White) }\end{array}$ & Light \\
\hline
\end{tabular}

Abbreviations: BisGMA - Bisphenol A dimethacrylate, BisEMA - Bisphenol A polyetheylene glycol diether dimethacrylate, UDMA - Urethane dimethacrylate, TEGDMA - triethyleneglycol dimethacrylate, PENTA - Dipentaerythritol penta acrylate monophosphate, DEGDMA - Diethylene Glycol Dimethacrylate, DMAEMA - N,N-Dimethylaminoethyl Methacrylate 
time $(10,20$, or 40 s) and spacing between the specimen and the curing unit light guide aperture ( $4 \mathrm{~mm}$ and $7 \mathrm{~mm}$ ). The sealants were chosen to form a representative selection of the commercially available types and compositions currently on the market.

The irradiance of the tested curing units was determined previously [18] by means of a calibrated fiber optic spectrally resolving radiometer equipped with an integrating sphere (S2000, Ocean Optics, USA) by considering the dimension differences between the curing unit tip and the sample. Irradiances passed through a round screen with an inner diameter of $4 \mathrm{~mm}$ (= dimension of cured samples) positioned at the center of the curing unit tip was thus calculated. At the present curing conditions the irradiance amounted $1000 \mathrm{~mW} / \mathrm{cm}^{2}$ at an exposure distance of $4 \mathrm{~mm}$ and $512 \mathrm{~mW} / \mathrm{cm}^{2}$ at an exposure distance of $7 \mathrm{~mm}$. Transferred to radiant exposure values (= Irradiance $x$ exposure time), the amount of light received by the materials at an exposure distance of $4 \mathrm{~mm}$ was $10.0 \mathrm{~J} / \mathrm{cm}^{2}, 20.0 \mathrm{~J} /$ $\mathrm{cm}^{2}$, and $40.0 \mathrm{~J} / \mathrm{cm}^{2}$ and $5.15 \mathrm{~J} / \mathrm{cm}^{2}, 10.3 \mathrm{~J} / \mathrm{cm}^{2}$ and $20.61 \mathrm{~J} / \mathrm{cm}^{2}$ at a distance of $7 \mathrm{~mm}$.

\subsection{Universal hardness measurement}

Samples from each sealant material were generated using a rod-shaped mold of $2 \times 5 \mathrm{~mm}$ and $2 \mathrm{~mm}$ depth (Fig 1). The sealant was bulk filled directly into the mold and the sample was immediately cured. The upper and lower surface was covered with a transparent matrix strip to ensure reproducible, smooth flat surfaces in the resulting samples. Two custom made adaptors were used to vary the spacing between the curing unit (Elipar Freelight 2, 3M ESPE, ca. $1,400 \mathrm{~mW} / \mathrm{cm}^{2}$, peak wavelength $460 \mathrm{~nm}$, serial \# 939820013826) light guide aperture (diameter 8 $\mathrm{mm}$ ) and the sample mold at a fixed distance of 4 $\mathrm{mm}$ and $7 \mathrm{~mm}$. For each product, exposure time (10, $20,40 \mathrm{~s})$ and exposure distance $(4 \mathrm{~mm}$ and $7 \mathrm{~mm}$ ) six samples were produced $(n=6)$. After curing the sample was immediately removed from the mold, the upper irradiated surface marked, then stored for $24 \mathrm{hrs}$ at high humidity (distilled water, $37^{\circ} \mathrm{C}$ ). Prior to measurement each sample was fixed to a glass slide and mounted in an automatic grinding machine (EXAKT 400CS Micro Grinding System EXAKT Technologies, Inc. OK, USA). Specimens were wet-ground with silicon carbide sand paper (grit size p2500 and p4000, LECO Corporation, USA) and polished with a diamond suspension (mean grain size: $1 \mu \mathrm{m}$ ) to remove the oxygen inhibited surface layer. Therefore, the grinding process was controlled electronically, comprising a pre-grinding of $100 \mu \mathrm{m}$ with the abrasive paper p2500 followed by additionally $100 \mu \mathrm{m}$ with $\mathrm{p} 4000$. The following polishing process lasted 2-3 minutes, until the surface was shiny. All measurements of HV and $E$ were performed using an automatic hardness indenter (Fischer-scope H100C, Fischer GmbH, Germany). Five measurements were made on each of the six samples per material and condition (total of 30 measurement positions per condition, 6 conditions per material, 13 materials $=2340$ measurements). The measurement positions were randomly selected and inspected
Table 2. Summary of the influence of factors material, exposure distance and exposure time on the micro-mechanical properties indentation modulus (E) and Vickers Hardness (HV). All values are $\eta_{p}{ }^{2^{*}}$.

\begin{tabular}{lcc}
\hline \multicolumn{1}{c}{ Factor } & E & HV \\
\hline Material & 0.939 & 0.927 \\
Exposure Distance & 0.049 & $\ldots$ \\
Exposure Time & 0.297 & 0.084 \\
\hline
\end{tabular}

* Only statistically significant $(a \leq 0.05)$ values are shown for each property. The higher the value of $\eta_{p}{ }^{2}$, the greater the influence of the selected factor on the measured property.

Table 3. Summary of the influence of factors exposure distance and exposure time on the micro-mechanical properties indentation modulus $(E)$ and Vickers Hardness (HV) for each material tested. All values are $\eta_{p}^{2^{*}}$.

\begin{tabular}{ccccc}
\hline & \multicolumn{2}{c}{$\begin{array}{c}\text { Exposure distance } \\
\eta_{p}{ }^{2}\end{array}$} & \multicolumn{2}{c}{ Exposure time $\mathbf{\eta}_{\mathrm{p}}{ }^{2}$} \\
\cline { 2 - 5 } Material & E & HV & E & HV \\
\hline Delton FS+ & 0.570 & 0.517 & $\ldots$ & 0.294 \\
Ultra Seal XT+ & 0.196 & 0.189 & 0.272 & $\ldots$ \\
Embrace & 0.218 & & 0.280 & 0.348 \\
Wetbond & & & & \\
Helioseal & $\ldots$ & $\ldots$ & 0.656 & 0.581 \\
Helioseal Clear & 0.513 & 0.432 & 0.289 & $\ldots$ \\
Helioseal F & $\ldots$ & $\ldots$ & 0.426 & $\ldots$ \\
Fissurit-F & $\ldots$ & 0.137 & 0.598 & 0.565 \\
Grandio Seal & 0.387 & $\ldots$ & 0.836 & $\ldots$ \\
Clinpro & $\ldots$ & $\ldots$ & 0.376 & 0.266 \\
Teethmate F1 & 0.588 & 0.311 & 0.740 & 0.783 \\
Delton & 0.184 & $\ldots$ & 0.496 & 0.213 \\
Dyract-Seal & 0.163 & $\ldots$ & 0.370 & $\ldots$ \\
lonosit-seal & $\ldots$ & $\ldots$ & 0.815 & 0.486 \\
\hline
\end{tabular}

* Only statistically significant $(a \leq 0.05)$ values are shown for each property. The higher the value of $\eta_{p}^{2}$, the greater the influence of the selected factor on the measured property.

with a microscope to ensure no air bubbles were present. The test load cycle was applied at a constant average velocity increasing from $0.4-500 \mathrm{mN}$, held constant at $500 \mathrm{mN}$ for $5 \mathrm{~s}$ and subsequently decreasing from $500-0.4 \mathrm{mN}$. During this cycle the load and penetration depth of the diamond indenter (square pyramid, angle of opposing faces at apex = $136^{\circ}$ ) were continuously monitored to follow the load-unload hysteresis.

Universal hardness is defined as the applied test force divided by the apparent area of indentation. A conversion factor between universal hardness and Vickers hardness was calculated and implemented into the software from a multiplicity of measurements stored in a database supplied by the manufacturer. In doing so, the results were documented in the more familiar Vickers hardness units. The indentation modulus (E) was calculated from the slope of the tangent to the indentationdepth curve at maximum force.

\subsection{Statistical analysis}

The results were assessed using a Generalized Linear 
Model (GLM). A multi-variant analysis was performed for the factors "material", "exposure distance" and "exposure time" and partial eta-squared $\left(\eta_{p}{ }^{2}\right)$ values determined (significance level $a \leq 0.05$ ). In addition for each material the factors "exposure distance" and "exposure time" were assessed using a uni-variant analysis with a $\eta_{p}^{2}$ statistic.

\section{Results}

For each material we measured the micro-mechanical properties HV and E for each exposure time (10, 20, $40 \mathrm{~s})$ and exposure distance (4 \& $7 \mathrm{~mm}$ ). The results of these tests are detailed in Tables 2-4.

The influence of the parameters "material", "exposure time", and "exposure distance" were analyzed statistically and compared using a GLM with multivariant analysis performed allowing partial eta squared $\left(n_{p}{ }^{2}\right)$ values to be determined (see Table 2 for summary of values). The significance levels of these factors were all $a \leq 0.05$, indicating that the null hypothesis - that no effect on micromechanical properties E and HV would be observed - could be rejected for all parameters with the exception of the values for exposure distance. The greatest influence on the measured micro-mechanical properties was displayed by the parameter "material" across all properties measured (consistently the highest values of $\eta_{p}{ }^{2}$ ). A significant effect of the "exposure time" was seen in both of the measured parameters - in order of descending magnitude E, HV. For the parameter "exposure distance" a statistical significance was observed in one of the two parameters - namely $\mathrm{E}$.

A detailed summary of all the statistical results on a material by material basis can be seen in Table 3. It details both of the measured parameters ( $E$ and HV) per material for both the factors exposure distance and exposure time. The table clearly shows that exposure time has a significant and higher effect than exposure distance in most analyzed materials. The detailed results of the measurements of $E$ and $H V$ values for all material and conditions are summarized as mean values from 6 samples tested at five different positions (Table 4). The measured $E$ values ranged from $2.34 \mathrm{GPa}$ (Embrace Wetbond at $20 \mathrm{~s}$ and $7 \mathrm{~mm}$ ) at the lower end to $9.70 \mathrm{GPa}$ (Grandio Seal at $40 \mathrm{~s}$ and $4 \mathrm{~mm}$ ) at the upper across all experimental parameters and materials. For HV the span of values ranged from $11.28 \mathrm{~N} / \mathrm{mm}^{2}$ (Embrace Wetbond, at 20 $\mathrm{s}$ and $7 \mathrm{~mm}$ ) for the lowest to $71.20 \mathrm{~N} / \mathrm{mm}^{2}$ (Grandio Seal, at $10 \mathrm{~s}$ and $4 \mathrm{~mm}$ ) for the highest.

Closely examining $E$ and comparing the $10 \mathrm{~s}$ and $40 \mathrm{~s}$ values at both the $4 \mathrm{~mm}$ and $7 \mathrm{~mm}$ exposure distances reveals that the average difference is $0.5 \mathrm{GPa}$ at 4 $\mathrm{mm}$ and $1.04 \mathrm{GPa}$ at $7 \mathrm{~mm}$. A similar inspection of the values for $\mathrm{HV}$ reveals that typically the values are reduced with increasing exposure time with few exceptions - only 2 or 4 of the materials showed an increase at either $4 \mathrm{~mm}$ or $7 \mathrm{~mm}$ exposure distances respectively.

\section{Discussion}

For this study we selected a representative cross section of thirteen commercially available pit and fissure sealants (see Table 1 for details). We investigated their micro-mechanical properties with respect to parameters clinically relevant to light activated curing. All experiments were executed using an automatic hardness indenter and micromechanical parameters determined from cured samples from each sealant material prepared under controlled laboratory conditions. We tested whether the three factors "material", "exposure time" and "exposure distance" had any significant influence on the micro-mechanical properties of the sealants.

The optical properties of the material in question play a role in the way in which curing light propagates through the sealant, both initially and as the polymerization reaction progresses. In fact, the results of this research clearly indicated that, not surprisingly, the material has the most profound effect on the measured micro-mechanical values. However, the relationship appears to be complex and it is difficult to see a direct correlation between the material composition and the $\mathrm{E} \& \mathrm{HV}$ values in the materials tested - with some exceptions - for example Grandio Seal has the highest level of filler content consistent and returns the highest HV of any tested material. The results of our present study indicate that, regardless of the material, increasing the exposure time leads in general to a small but significant increase in the $E$ values. Interestingly we found that for HV values the exposure distance had no significant effect, whereas exposure time did albeit less so than for $E$. Based on previous findings [18], the difference in irradiance between the 4 and $7 \mathrm{~mm}$ positions is on the order of approximately 400 $\mathrm{mW} / \mathrm{cm}^{2}$ lower at the more elevated position for the hand-held curing device employed in the current study. A simple conversion of the irradiance values $\left(\mathrm{mW} / \mathrm{cm}^{2}\right)$ employed in this study to examine the total energy equivalents delivered per $\mathrm{cm}^{2}$ (radiant exposure, $\mathrm{J} / \mathrm{cm}^{2}$ ) shows that approximately the same total "dose" of light energy was applied under the following conditions: $4 \mathrm{~mm} 10 \mathrm{~s}\left(10 \mathrm{~J} / \mathrm{cm}^{2}\right) \approx 7$ $\mathrm{mm} 20 \mathrm{~s}\left(10.3 \mathrm{~J} / \mathrm{cm}^{2}\right)$ and $4 \mathrm{~mm} 20 \mathrm{~s}\left(20 \mathrm{~J} / \mathrm{cm}^{2}\right) \approx 7$ $\mathrm{mm} 40 \mathrm{~s}\left(20.6 \mathrm{~J} / \mathrm{cm}^{2}\right)$. Previous findings on the exact same group of sealant materials with the same set of variables [23] revealed that for a given sealant material the degree of cure after 5 minutes was more strongly influenced by the exposure time rather than the exposure distance. The rates of curing, reached a maximum after ca. 5 seconds and remained constant for ca. $15 \mathrm{~s}$ before slowing to exhaustion (unpublished observations). Minor differences in the final degree of the cure were typically observed for each material. In the current study, a similar observation can be made on a per material basis respect to the $E$ and $H V$ values. Thus, at face value it would appear that the energy dose, when equivalent, leads to similar micromechanical properties for a given material. However, this applies, only for the materials Embrace, Teethmate F and Delton. Previous investigations with the degree of cure measurements also revealed similar findings in this respect [23]. Thus, it would seem for a given material that if the total amount of energy supplied is constant then similar micromechanical properties and degree of cure are observed. This is despite variations in the 
Table4. Summary of the results showing the measurements of micro-mechanical properties indentation modulus (E) andVickers Hardness (HV) for each material tested for each exposure distance and exposure time. All values are the mean of measurements on 6 samples (for each sample 5 positions were tested) for each material and condition. The standard deviation is indicated in brackets.

\begin{tabular}{|c|c|c|c|c|c|c|}
\hline Material & & Time (s) & E 4 mm (GPa) & E 7 mm (GPa) & HV 4 mm (N/mm²) & HV $7 \mathrm{~mm}\left(\mathrm{~N} / \mathrm{mm}^{2}\right)$ \\
\hline \multirow{3}{*}{ Delton FS+ } & \multirow{3}{*}{0} & 10 & $7.35(0.72)$ & $6.30(0.54)$ & $49.39(3.51)$ & $45.65(4.15)$ \\
\hline & & 20 & $7.90(0.45)$ & $6.07(1.03)$ & $48.46(3.46)$ & 37.71 (5.74) \\
\hline & & 40 & $7.42(0.36)$ & $6.34(0.40)$ & $45.95(1.63)$ & $39.58(2.05)$ \\
\hline \multirow{3}{*}{ Ultra Seal XT } & \multirow{3}{*}{0} & 10 & $6.46(1.84)$ & $6.26(1.21)$ & $39.89(11.55)$ & $39.50(8.22)$ \\
\hline & & 20 & $6.22(0.78)$ & $8.88(0.53)$ & $35.02(4.34)$ & $49.33(2.91)$ \\
\hline & & 40 & $7.57(1.32)$ & $8.72(1.77)$ & $42.02(6.80)$ & $48.73(9.52)$ \\
\hline \multirow{3}{*}{ Embrace } & \multirow{3}{*}{0} & 10 & $2.86(0.18)$ & $2.80(0.25)$ & $15.51(2.55)$ & $14.20(1.99)$ \\
\hline & & 20 & $2.82(0.21)$ & $2.34(0.24)$ & $13.52(1.16)$ & $11.28(1.10)$ \\
\hline & & 40 & $2.79(0.14)$ & $2.77(0.12)$ & $13.00(0.64)$ & $13.65(0.60)$ \\
\hline \multirow{3}{*}{ Helioseal } & \multirow{3}{*}{0} & 10 & $3.18(0.17)$ & $2.74(0.43)$ & $26.43(3.33)$ & $29.17(3.03)$ \\
\hline & & 20 & $3.55(0.05)$ & $3.47(0.16)$ & $23.59(0.41)$ & $23.70(1.76)$ \\
\hline & & 40 & $3.45(0.09)$ & $3.59(0.09)$ & $22.39(0.67)$ & $23.42(0.14)$ \\
\hline \multirow{3}{*}{ Helioseal Clear } & \multirow{3}{*}{0} & 10 & $3.74(0.05)$ & $3.36(0.08)$ & $25.60(1.32)$ & $21.47(1.44)$ \\
\hline & & 20 & $3.63(0.15)$ & $3.57(0.10)$ & $23.83(1.64)$ & $22.56(1.32)$ \\
\hline & & 40 & $3.75(0.73)$ & $3.63(0.11)$ & $24.53(0.77)$ & $23.69(1.17)$ \\
\hline \multirow{3}{*}{ Helioseal F } & \multirow{3}{*}{ ? } & 10 & $4.88(0.29)$ & $4.28(0.44)$ & $27.86(3.39)$ & $27.38(4.46)$ \\
\hline & & 20 & $5.04(0.25)$ & $5.23(0.24)$ & $25.90(1.96)$ & $27.38(2.28)$ \\
\hline & & 40 & $4.98(0.36)$ & $5.23(0.31)$ & $24.94(3.21)$ & $27.38(2.85)$ \\
\hline \multirow{3}{*}{ Fissurit F } & \multirow{3}{*}{0} & 10 & $3.78(0.81)$ & $3.18(0.41)$ & $32.43(5.41)$ & 38.74 (3.84) \\
\hline & & 20 & $4.40(0.05)$ & $4.21(0.05)$ & $29.87(0.24)$ & $29.90(0.83)$ \\
\hline & & 40 & $4.40(0.07)$ & $4.42(0.07)$ & $29.40(0.43)$ & $29.05(0.55)$ \\
\hline \multirow{3}{*}{ Grandio Seal } & \multirow{3}{*}{$?$} & 10 & $8.12(0.66)$ & $6.39(0.58)$ & $71.20(9.02)$ & $67.82(16.99)$ \\
\hline & & 20 & $9.61(0.28)$ & $9.42(0.60)$ & $67.40(2.94)$ & 71.07 (5.92) \\
\hline & & 40 & $9.70(0.51)$ & $9.36(0.40)$ & $65.65(4.43)$ & 63.25 (4.44) \\
\hline \multirow{3}{*}{ Clinpro } & \multirow{3}{*}{0} & 10 & $3.84(0.09)$ & $3.80(0.05)$ & $24.13(0.52)$ & $23.91(0.96)$ \\
\hline & & 20 & $3.98(0.13)$ & $3.92(0.05)$ & $25.25(0.33)$ & $24.58(0.50)$ \\
\hline & & 40 & $3.95(0.09)$ & $3.89(0.04)$ & 24.04 (1.15) & $24.15(0.64)$ \\
\hline \multirow{3}{*}{ Teethmate F1 } & \multirow{3}{*}{$\stackrel{0}{0}$} & 10 & $3.50(0.04)$ & $3.05(0.23)$ & $26.32(0.77)$ & $34.70(3.44)$ \\
\hline & & 20 & $3.66(0.05)$ & $3.53(0.04)$ & $25.67(0.28)$ & $24.05(1.32)$ \\
\hline & & 40 & $3.67(0.04)$ & $3.57(0.06)$ & $25.33(0.11)$ & $24.26(0.36)$ \\
\hline \multirow{3}{*}{ Delton } & \multirow{3}{*}{0} & 10 & $3.52(0.17)$ & $3.15(0.52)$ & $28.67(0.70)$ & 31.40 (8.99) \\
\hline & & 20 & $3.90(0.14)$ & $3.59(0.12)$ & $27.51(0.59)$ & 27.79 (1.07) \\
\hline & & 40 & $3.81(0.11)$ & $3.87(0.64)$ & $25.76(0.87)$ & $25.62(0.83)$ \\
\hline \multirow{3}{*}{ Dyract Seal } & \multirow{3}{*}{0} & 10 & $4.80(0.40)$ & $3.06(0.34)$ & $31.47(2.18)$ & $22.91(1.84)$ \\
\hline & & 20 & $3.85(0.18)$ & $4.10(0.29)$ & $22.91(2.47)$ & $26.97(2.53)$ \\
\hline & & 40 & $4.31(0.41)$ & $4.81(0.68)$ & $25.18(2.60)$ & $28.61(4.56)$ \\
\hline \multirow{3}{*}{ Ionosit Seal } & ○ & 10 & $4.49(0.29)$ & $4.74(0.17)$ & $33.55(0.99)$ & $38.43(2.88)$ \\
\hline & \multirow{2}{*}{0} & 20 & $5.29(0.19)$ & $5.07(0.19)$ & $31.45(2.30)$ & $33.46(1.35)$ \\
\hline & & 40 & $5.71(0.10)$ & $5.31(0.18)$ & $34.14(1.16)$ & $31.01(1.65)$ \\
\hline
\end{tabular}

Material composition codes:
with filler
without filler
with Fluoride
- without Fluoride Compomers 
way in which this energy is delivered (exposure time or exposure distance) under controlled laboratory conditions. In contrast, in the materials Delton FS+, Ultra Seal XT+ and Dyract-Seal, both parameters HV and E evidenced significant higher values when at a comparable radiant exposure, the exposure time was higher $(p<0.001)$. The statement above applies only for the lower radiant exposure $\left(10 \mathrm{~J} / \mathrm{cm}^{2}\right)$ in Helioseal and Helioseal Clear, while at a higher radiant exposure $\left(20 \mathrm{~J} / \mathrm{cm}^{2}\right)$ values were statistical similar. For materials Helioseal F, Fissurit-F, Grandio Seal, Clinpro and lonosit the above afirmations are valid only for the property $E$, while HV was similar within one radiant exposure. The effect of similar radiant exposure at different curing time or exposure distance is thus material dependent and cannot be related to the filler content. Moreover, in the clinical situation other factors, such as patient compliance, choice and handling of the equipment, lead to a recommendation to optimize such parameters for the chosen material. Interestingly, research into the efficiency of light activated polymerization has shown that this may reach saturation such that higher intensities or exposure times no longer have any effect on the material properties [19].

Furthermore, it has been suggested that too high light levels have a number of detrimental effects on the polymerization reaction. The creation of the excited state of the photo-initiator species reaches saturation as the kinetics of its decay and conversion are essentially rate limiting. Hence, it takes time for a partial steady state to be reached in which the photo-initiator can either be converted to a radical initiator or recycled to its ground state. Too high rates of initiator production can lead to increased probabilities of mutual annihilation that result in reduced polymer chain length. Hence, this reduces network formation within the curing material leading to poorer mechanical properties. Thus, longer exposures to high intensity light sources may be counterproductive in this respect. It might also be speculated that the light transmission characteristics of the materials change during the process of polymerization and that such modifications can also account for or contribute to these observations. In composite materials a significant contribution to this is assigned to the differences in the refractive index of the individual components and the way that this relationship changes during the course of polymerization and curing of the resin-based matrix [24]. In work previously published [23] we have investigated how the degree of cure (DC) after a 5-minute time course varies with the same set of experimental parameters and materials described here. Again, as in the current study the factor material had the most significant influence on DC, but a comparative correlation between filler content and DC, for example, does not reveal a distinct pattern. Thus, this would suggest that for a given sealant material brand an optimized curing protocol should be followed. In respect to the clinical function of pit and fissure sealants, the more important aspect is the ability to form a tight seal and plug between tooth and resin without any gap that might provide a niche to bacteria. Hence, material shrinkage and adhesion to the target are more important than absolute hardness for example. Typically, filled resins have a higher viscosity and a different characteristic in their ability to flow into and penetrate narrow spaces which may have an influence on retention rates [25]. However, the filler has another significant influence on these sealants. Typically, filled sealants are more resistant to abrasion meaning that not only occlusal control but also occlusal adjustment must be routinely employed when applying a filled sealant [13]. Potentially, this makes the process more time consuming whilst it also excludes unqualified auxiliaries from preforming the task.

This probably leads to a significant impact on the number patients treated in some localities. In general checking for occlusion anomalies is very important in pit and fissures treatments of this type, as the materials are generally not formulated to withstand high biting forces and potentially fail. For the unfilled sealants the situation is more forgiving and poor occlusal adjustment, although highly undesirable, is probably short lived as local occlusion anomalies are quickly worn within 24-48 hours [26] (provided the sealant is not lost completely or partially during this period!). Of course, successful sealant application is more than just materials science. In part the skill and knowledge of the practitioner paired with the appropriate application protocol are just as paramount in this respect [6].

\section{Conclusions}

The presented data allow rejecting all specified null hypothesis. It can therefore be concluded that:

- Micromechanical properties are significantly influenced be the factor "material". On the other hand "exposure time" has inverse effects on $E$ and HV and "exposure distance" only a minor effect on $E$.

- Within the bounds of this study exposure time has a more significant effect on micromechanical properties in comparison to exposure distance.

- On the basis of these findings under comparable clinical conditions a curing time of at least $20 \mathrm{~s}$ at $4 \mathrm{~mm}$ is probably to be recommended for the majority of the tested materials, providing clinical conditions are comparable to those in the described study.

- Material has the most significant effect on the measured properties. This suggests that for a given sealant brand individually optimized curing protocols need to be employed.

\section{Author Contributions}

$\mathrm{NI}$ : designed the study, provided the infrastructure (devices, materials), developed the measurement methods, supervised the experiment, performed statistics, drafted and critically revised the manuscript. $\mathrm{MH}$ : performed the measurements, 
collected data, and wrote the manuscript.

\section{Acknowledgments \\ Not applicable.}

\section{References}

1. Cueto El, Buonocore MG. Sealing of pits and fissures with an adhesive resin: its use in caries prevention. $J$ Am Dent Assoc. 1967;75(1):121-128.

[Full text links] [PubMed] Google Scholar Scopus

2. Rock WP, Anderson RJ. A review of published fissure sealant trials using multiple regression analysis. J Dent. 1982;10(1):3943.

[Full text links] [PubMed] Google Scholar Scopus

3. Llodra JC, Bravo M, Delgado-Rodriguez M, et al. Factors influencing the effectiveness of sealants--a meta-analysis. Community Dent Oral Epidemiol. 1993;21(5):261-268.

[Full text links] [PubMed] Google Scholar Scopus

4. Mejare I, Lingstrom P, Petersson LG, et al. Caries-preventive effect of fissure sealants: a systematic review. Acta Odontol Scand. 2003;61(6):321-330.

[PubMed] Google Scholar Scopus

5. Ahovuo-Saloranta A, Forss H, Walsh T, et al. Pit and fissure sealants for preventing dental decay in permanent teeth. Cochrane Database Syst Rev. 2017;7:CD001830. [CrossRef] [PubMed] Google Scholar Scopus

6. Beauchamp J, Caufield PW, Crall JJ, et al. Evidence-based clinical recommendations for the use of pit-and-fissure sealants: a report of the American Dental Association Council on Scientific Affairs. J Am Dent Assoc. 2008;139(3):257-268. [Full text links] [PubMed] Google Scholar Scopus

7. Kuhnisch J, Mansmann U, Heinrich-Weltzien R, Hickel R. Longevity of materials for pit and fissure sealing-results from a meta-analysis. Dent Mater. 2012;28(3):298-303.

[CrossRef] [PubMed] Google Scholar Scopus

8. Simonsen RJ, Neal RC. A review of the clinical application and performance of pit and fissure sealants. Aust Dent J. 2011;56 Suppl 1:45-58.

[CrossRef] [PubMed] Google Scholar Scopus

9. Simonsen RJ. Retention and effectiveness of dental sealant after 15 years. J Am Dent Assoc. 1991;122(10):34-42. [Full text links] [PubMed] Google Scholar Scopus

10. Rock WP, Potts AJ, Marchment MD, et al. The visibility of clear and opaque fissure sealants. Br Dent J. 1989;167(11):395-396. [PubMed] Google Scholar Scopus

11. Johnson WW, Armanazi Y, Sharp H. Sealant leakage with and without isolation. J Tenn Dent Assoc. 1997;77(1):32-34. [PubMed] Google Scholar Scopus

12. Beauchamp J, Caufield PW, Crall J, et al. Evidence-based clinical recommendations for the use of pit-and-fissure sealants: a report of the American Dental Association Council on Scientific Affairs. Dent Clin North Am. 2009;53(1):131-147. [CrossRef] [PubMed] Google Scholar Scopus
13. Stach DJ, Hatch RA, Tilliss TS, Cross-Poline GN. Change in occlusal height resulting from placement of pit and fissure sealants. J Prosthet Dent. 1992;68(5):750-753. [Full text links] [PubMed] Google Scholar Scopus

14. Tilliss TS, Stach DJ, Hatch RA, Cross-Poline GN. Occlusal discrepancies after sealant therapy. J Prosthet Dent. 1992;68(2):223-228.

[Full text links] [PubMed] Google Scholar Scopus

15. Aravamudhan K, Floyd CJ, Rakowski D, et al. Light-emitting diode curing light irradiance and polymerization of resinbased composite. J Am Dent Assoc. 2006;137(2):213-223.

[Full text links] [PubMed] Google Scholar Scopus

16. Neumann MG, Miranda WG Jr, Schmitt CC, et al. Molar extinction coefficients and the photon absorption efficiency of dental photoinitiators and light curing units. J Dent. 2005;33(6):525-532

[CrossRef] [PubMed] Google Scholar Scopus

17. Rueggeberg FA. State-of-the-art: dental photocuring--a review. Dent Mater. 2011;27(1):39-52.

[CrossRef] [PubMed] Google Scholar Scopus

18. Rencz A, Hickel R, Ilie N. Curing efficiency of modern LED units. Clin Oral Investig. 2012;16(1):173-179. [CrossRef] [PubMed] Google Scholar Scopus

19. Ledwith A. Photoinitiation of polymerization. J App/ Chem 1977:49:431-41

20. Musanje L, Darvell BW. Polymerization of resin composite restorative materials: exposure reciprocity. Dent Mater. 2003;19(6):531-541

[Full text links] [PubMed] Google Scholar Scopus

21. Caughman WF, Rueggeberg FA, Curtis JW Jr. Clinical guidelines for photocuring restorative resins. J Am Dent Assoc. 1995;126(9):1280-1282, 1284, 1286.

[Full text links] [PubMed] Google Scholar Scopus

22. Rueggeberg FA, Jordan DM. Effect of light-tip distance on polymerization of resin composite. Int J Prosthodont. 1993;6(4):364-370.

[PubMed] Google Scholar Scopus

23. Holroyd M, llie N. Effects of exposure time and exposure distance on the degree of cure in light-activated pit and fissure sealants. J Dent. 2013;41(12):1222-1228. [CrossRef] [PubMed] Google Scholar Scopus

24. Shortall AC, Palin WM, Burtscher P. Refractive index mismatch and monomer reactivity influence composite curing depth. $J$ Dent Res. 2008;87(1):84-88. [CrossRef] [PubMed] Google Scholar Scopus

25. Hatibovic-Kofman S, Wright GZ, Braverman I. Microleakage of sealants after conventional, bur, and air-abrasion preparation of pits and fissures. Pediatr Dent. 1998;20(3):173-176 [PubMed] Google Scholar Scopus

26. Handelman SL, Buonocore MG, Heseck DJ. A preliminary report on the effect of fissure sealant on bacteria in dental caries. J Prosthet Dent. 1972;27(4):390-392. [Full text links] [PubMed] Google Scholar Scopus

\section{Maria HOLROYD \\ DDS, PhD Student \\ Department of Operative / Restorative Dentistry, Periodontology \& Pedodontics Faculty of Medicine , Ludwig-Maximillians University of Munich Munich, Germany}

Maria Holroyd attended the Ludwig-Maximillians-University in Munich where she took her graduation examinations and qualified as a dentist in 2012. Since then she has worked as a dental practitioner and is currently finalizing her dissertation in the department of Operative / Restorative Dentistry, Periodontology \& Pedodontics in Munich to obtain her medical doctorate. 


\section{0uestions}

\section{The Following statements are valid for commercially available pit and fissure sealants:}

Da. Opaque sealants allow a more reliable clinical assessment of retention;

b. Only transparent ones are recommended, based on esthetical considerations;

ac. No filler content is identified;

$\square$ d. Only a universal, transparent shade is available.

\section{Pit and fissure sealants are subdivided with respect to following particularities:}

口a. Pit and fissure sealants are a unitary material category, with less difference among individual materials;

ab. Presence of filler, Fluoride, chemical composition;

ac. Low and fast curing materials;

d. Amount of light they need for polymerization.

\section{It has been observed in pit and fissure sealants that:}

a. Exposure distance had a low influence on their mechanical properties;

b. Exposure time has a low influence on their mechanical properties;

ac. The properties of the materials are not influenced by the way they are curing;

$\square d$. The filler content and not the amount of light the materials receive is important.

\section{What is clinically recommended for pit and fissure sealants?}

Da. Optimized curing protocols need to be employed, but a curing time of at least $20 \mathrm{~s}$ is recommended for the majority of the tested materials;

b. 5 s of curing are considered sufficient, particularly in non-cooperative children;

ac. A curing time of at least $60 \mathrm{~s}$;

$\square d$. The exposure time has no influence on the final properties.

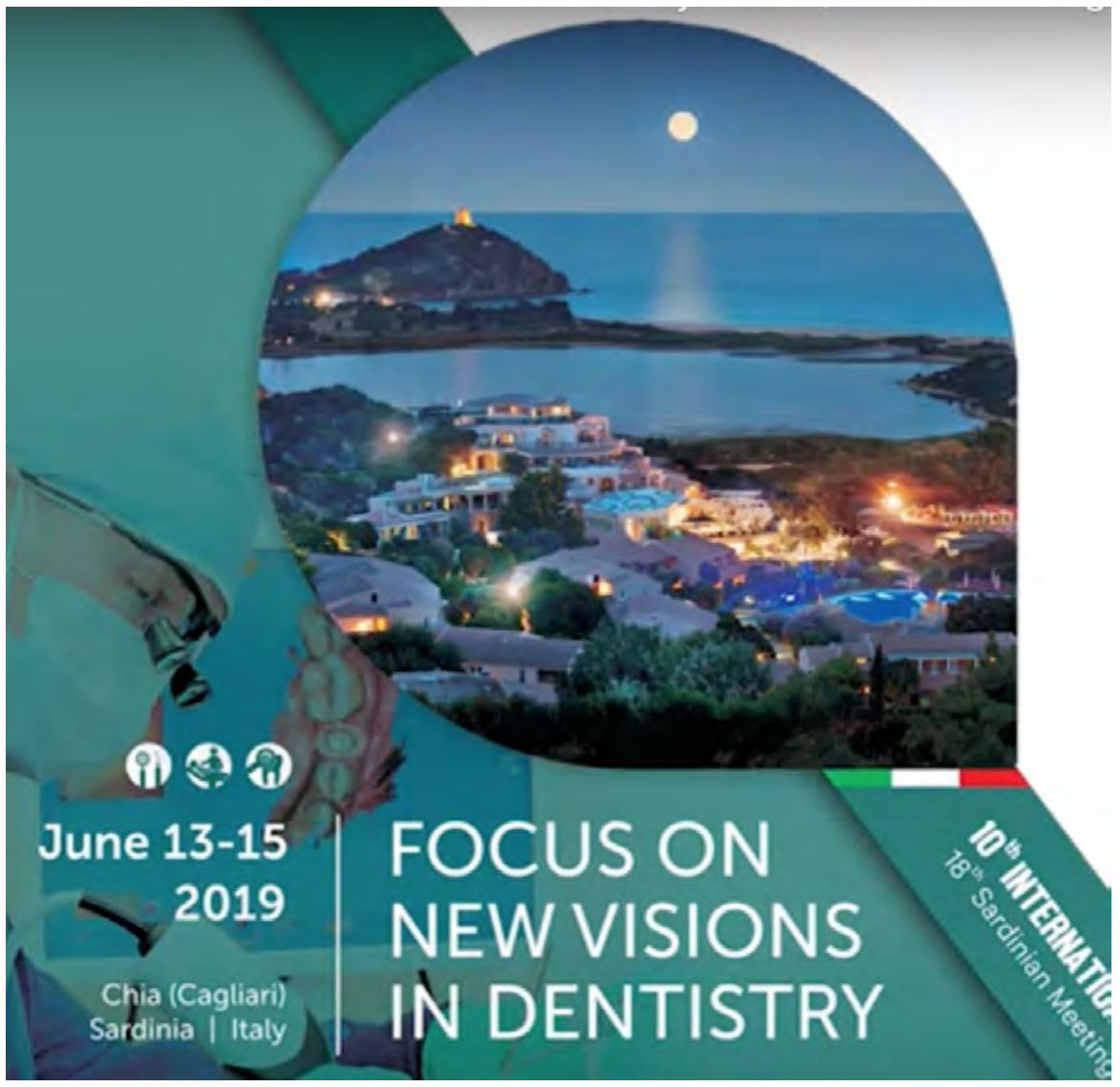

http://congressaio.it/programma.php 